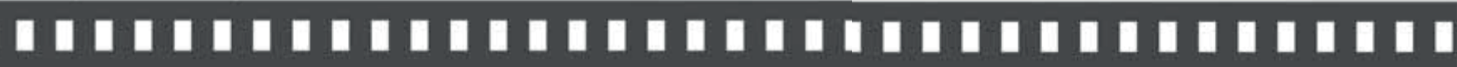

\author{
Representación y percepción \\ de emoción de la alegría en la \\ fotografía publicitaria
}

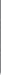

\author{
Esther MartÍnez Pastor \\ Paloma Díaz Lobón
}

Artículo recibido en: 01/06/2017

Artículo aprobado en: 02/02/2018 


\title{
Representación y percepción de emoción de la alegría en la fotografía publicitaria
}

Representation and perception of the happiness emotion in the advertising photography

\author{
Esther MartÍnez Pastor" \\ Paloma Díaz Lobón ${ }^{* *}$
}

Resumen: Este artículo analiza cómo se representa y se percibe la alegría en la fotografía publicitaria en la prensa española. Con una muestra están 112 anuncios fotográficos de prensa y 60 encuestados que indicaban qué emociones percibían de la muestra. Se destaca que la publicidad fotográfica española es emotiva destacándose la alegría con diferencias de género y se han identificado productos que vinculan su marca con esta emoción.

Palabras Clave: Publicidad. Fotografía. Emoción. Alegría. Percepción. Representación.

Abstract: This article examines how happiness is perceived and how it is represented in advertising spanish photography. With a sample are 112 photography ads and a panel of 60 respondents a questionnaire to know their emotional perceptions. Among the most important results it emerged that the Spanish advertising is standing emotional cheerfulness, the differences gender and types of products that connect your brand with the emotion cheerfulness.

Keywords: Advertising. Photography. Emotion. Happiness. Perception. Representation.

*Profesora de Ciencias de la Comunicación. Universidad Rey Juan Carlos (URJC), Madrid, España-E-mail: esther.martinez.pastor@urjc.es

**Organizador de eventos. Madrid y Región, España. 


\section{Introducción}

La publicidad y la emoción son un binomio cada vez más indisoluble. La tendencia de los mensajes publicitarios es convertir que la imagen visual sensibilice al corazón (Pepinou 1976). De hecho, son numerosos los estudios que han analizado el uso de las emociones en la publicidad (HOLBROOK; BATRA, 1987; KAMP; MACINNIS, 1995; OLNEY; HOLBROOK; BATRA, 1991), tanto positivas como negativas (CHUANG; LIN, 2007; FARRELLY et al., 2012; LEWIS; WATSON; WHITE, 2010). Las emociones son el resultado de un proceso multidimensional que surge de un estímulo desencadenante, ya sea interno o externo, que al ser procesado por componentes tanto cognitivos como subjetivos, hace que el sujeto experimente una sensación agradable o desagradable de corta duración pero intensidad alta, generándole unos cambios fisiológicos, conductuales y faciales, para facilitar y promover, la comunicación y la adaptación del ser humano con su entorno (CHÓLIZ MONTAÑÉS, 2005; GARCÍA FERNÁNDEZ ABASCAL et al., 2010; KLEINGINNA; KLEINGINNA, 1981; SALANOVA; MARTÍNEZ; LLORENS, 2004; VECINA JIMÉNEZ, 2006). Las emociones pueden ser positivas o negativas y, de acuerdo con la literatura, identificarlas también como básicas o secundarias (FRIJDA, 2001; GARCÍAFERNÁNDEZABASCAL et al., 2010; HAMM; SHUPP; WEIKE, 2003). Las primeras aparecen en los primeros años de vida sin necesidad de que intervenga la cultura. Estas emociones, que se distinguen fácilmente por su expresión facial universal, son: la ira, la alegría, el miedo, el asco, la sorpresa y la tristeza (ANDRADE CABRERA; MORALES 
GARCÍA, 2012; CHÓLIZ MONTAÑÉS, 2005; EKMAN, 1992; GARCÍA FERNÁNDEZ ABASCAL et al., 2010). Mientras que las emociones secundarias, de carácter moral o social, son aquellas que derivan de la mezcla de emociones primarias y/o del resultado de los procesos de maduración y socialización del individuo (ANDRADE CABRERA; MORALES GARCÍA, 2012; CHÓLIZ MONTAÑÉS, 2005). Las emociones cumplen además, unas funciones básicas que son: la función de adaptación, la función social y la función motivacional (REEVE, 1994). Todas ellas preparan, advierten y proveen al sujeto de la respuesta más adecuada para cada momento (ANDRADE CABRERA; MORALES GARCÍA 2012; GARCÍA FERNÁNDEZ ABASCAL et al., 2010).

Este estudio se centrará solo en una de las emociones primarias de carácter positivo, la alegría, pero específicamente vinculada a la publicidad. Se ha seleccionado esta emoción porque en nuestra sociedad hiperconsumista, las emociones positivas son las imperantes frente a las negativas, y los universos simbólicos representados en la publicidad se recrean en el ámbito del placer y de la diversión (LIPOVESKY, 2007). El término de la alegría proviene del latín alicer o alecris, que significa "rápido, vivaz o animado", y es una emoción que se produce en el interior de cada persona y que, por lo tanto, adquiere un valor subjetivo diferente (CHÓLIZ MONTAÑÉS, 2005; REEVE, 1992). Sus características la definen como una emoción: 1) agradable e innata, por lo que formaría parte tanto de las emociones primarias, como de las positivas; que 2) requiere de algún estímulo desencadenante que la provoque, como un placer físico o vivencia divertida, grata o apacible; la reducción en la experimentación de una emoción 
negativa o malestar; la consecución de un logro importante etc.; 3) el origen de la alegría siempre es interior y es subjetiva; 4) produce innumerables efectos, como conductas positivas, la mejora de la memoria, facilita la resolución de problemas y comportamientos altruistas, entre otros (LÓPEZ-CEPERO BORREGO; FERNÁNDEZ JIMÉNEZ; SENÍN CALDERÓN, 2009; GARCÍA FERNÁNDEZ ABASCAL et al., 2010; VECINA JIMÉNEZ, 2006); 5) es identificable por los cambios fisiológicos o corporales que provoca, como su expresión más reconocida, la sonrisa (GARCÍA FERNÁNDEZ ABASCAL et al., 2009, 2010) cuya duración es generalmente corta, y de intensidad variable (gozo-éxtasis), dependiendo del tipo de desencadenante (GARCÍA FERNÁNDEZ ABASCAL et al., 2010). Los estudios de la alegría han proliferado en los últimos años, porque se ha demostrado que las emociones positivas ayudan a aumentar la calidad de vida de los sujetos y a tener una mejor sociabilidad (GARCÍA FERNÁNDEZABASCAL, 2009; LÓPEZ-CEPERO BORREGO; FERNÁNDEZ JIMÉNEZ; SENÍN CALDERÓN, 2009). Por este motivo, la publicidad ha visto que esta emoción puede ser muy atractiva para sustentar sus campañas y generar así una imagen de marca favorable llevando a cabo estrategias publicitarias emocionales (LÓPEZ VÁZQUEZ 2007; TELLIS; REDONDO, 2002) y la diferenciación entre la racionalidad o emotividad de la comunicación persuasiva publicitaria (BRIÑOL, et al., 2007). Los estudios relativos a las emociones y a la publicidad, son muy diversos (HOLBROOK; BATRA, 1987; HOLBROOK; O’SHAUGHNESSY, 1984; MARTÍNEZ-PASTOR; MONTE-VOZMEDIANO, 2015; MARTÍNEZ RODRIGO; SEGURA GARCÍA, 2013), sin embargo 
solo nos centraremos en la publicidad fotográfica que comunica desde la alegría, generando un empatía positiva con el target al que se dirige (BERMEJO BERROS, 2010; CODELUPPI, 2007). Se han realizado diferentes investigaciones, focalizadas en la utilización de la alegría, como recurso publicitario en distintos sectores. En la publicidad de juguetes para los niños, es común encontrar esta emoción para conectar con el público objetivo, representado por escenarios de alegría y diversión, o utilizando personajes con voces de tonojovial y vivaz(GAONAPISONERO; MARTÍNEZPASTOR, 2008; MARTÍNEZ-PASTOR; MONTE-VOZMEDIANO, 2015; MONTOYA VILAR, 2000). La alegría, también ha sido estudiada vinculada al sector de la mujer. La publicidad dirigida a este target las suele representar con un estado de ánimo alegre, y vinculada a un estilo vida jovial al margen de todo lo que pueda sugerir tristeza o negatividad (CÁCERES ZAPATERO; DÍAZ SOLOAGA, 2008). Otros estudios sostienen que la mujer en la publicidad fotográfica de moda de lujo, es mostrada en una actitud alegre, asociada a un tipo de vida tradicional y convencional, que representa el deseo de toda mujer (DÍAZ SOLOAGA, 2007). En la publicidad de alcohol y tabaco, la alegría se utiliza como herramienta persuasiva asociada al liderazgo, la diversión y el éxito social, que todo individuo desea alcanzar (SÁNCHEZ GARCÍA, 2002), además los personajes representados se caracterizan por mostrarse alegres, desenfadados y optimistas (RAMOS SERRANO; RUBIO HERNÁNDEZ, 2011). De igual modo, la publicidad electoral (SCRETTI, 2012) o la dirigida a la integración de la inmigración (GAONA PISONERO; MARTINEZ PASTOR, 2008), se vale de la emoción de la alegría para conectar con su target. Esto indica que el uso de la emoción 
de la alegría en publicidad es recurrente para cualquier sector y target. Por este motivo, esta investigación se centrará en cómo se percibe la emoción en publicidad, independientemente del sector y del público objetivo.

\section{Metodología}

La metodología realizada para el análisis es una aproximación metodológica cuantitativa y cualitativa. El estudio partió de la selección de una muestra de anuncios gráficos de diferentes sectores, difundidos durante el año 2014-15 en diferentes revistas españolas. Posteriormente, se elaboró un cuestionario a partir de la muestra de anuncios, para conocer la percepción de los sujetos ante esta publicidad fotográfica.

\section{Objetivos e Hipótesis}

El propósito de la presente investigación es conocer la percepción de la emoción de la alegría en la publicidad fotográfica española actual. Se parte de la hipótesis de que la publicidad fotográfica española no destaca ni por su carácter emotivo, ni por la sugestión de la emoción de la alegría. Solamente se percibe la alegría mediante determinados elementos compositivos. Los objetivos específicos de la investigación son:

- Averiguar si la alegría en publicidad fotográfica está relacionada con algún tipo concreto de productos, publicaciones, o target. 
- Conocer qué elementos compositivos de la imagen resultan claves para sugerir la alegría en publicidad fotográfica española.

- Saber cómo se representa y cómo se utiliza la alegría en la publicidad fotográfica de la prensa española.

- Conocer si la publicidad fotográfica española utiliza el código visual como principal hilo conductor del mensaje global.

\section{Muestra}

La muestra publicitaria seleccionada fue la prensa fotográfica española siguiendo un criterio estratégico-intencional con el objeto de contener la mayor variedad de anuncios publicitarios de distintos sectores y target. Seleccionamos dicha muestra por ser uno de los medios más utilizados tanto por la audiencia como por la industria publicitaria, a pesar de que en el último año la inversión publicitaria de las mismas haya descendido dentro de los medios convencionales - InfoAdex (SÁNCHEZ REVILLA, 2014). En relación a las fotográficas publicitarias, el universo de la investigación podría abarcar toda la prensa española. Sin embargo, debido a la escasez de medios disponibles y para acotar los resultados, sólo se recopiló una muestra formada por 112 anuncios gráficos, correspondientes a revistas y suplementos de prensa española. En lo referente a las revistas que compusieron la muestra del estudio, éstas fueron seleccionadas aleatoriamente para garantizar tanto un target (público femenino, público masculino, público no diferenciado) como una temática variada (moda, belleza, 
actualidad, cultura, corazón, etc.). Se utilizaron 8 revistas diferentes: Hola, Cuore Stilo, Woman Madame Figaro, Icon, El País Semanal, Cuore, Muy Interesante y S Moda. Es decir, 5 revistas enfocadas a un público femenino, 1 revista enfocada a un público masculino, $\mathrm{y}$ 2 revistas enfocadas a ambos (tanto a un público femenino, como masculino). La muestra de revistas seleccionadas corresponde con números de Noviembre (2014) a Febrero (2015). Se eligió este lapso de tiempo por coincidir con la campaña navideña, momento en el que aumenta la publicidad por el consumo cuantitativo de las fiestas navideñas. A continuación, se expone una tabla que resume la muestra en cuanto a las publicaciones utilizadas.

Se utilizaron todos los anuncios de las revistas que constituyeron la muestra, salvo aquellos anuncios que: hicieran autopromoción de la revista en cuestión (publicidad de suscripciones y/o cartillas promocionales); aquellos que ocuparan menos de media página; las campañas repetidas; o toda publicidad que no fuera convencional (integrada, publirreportaje, o autorreferencial) por la intencionalidad encubierta de este tipo de publicidad (BERMEJO BERROS, 2010). A continuación, se observa en la tabla siguiente cómo se organizan los anuncios utilizados en la muestra, según su sector y target, para poder obtener más conclusiones a partir de los datos extraídos de la encuesta. En la columna "indefinido" se encuentran los anuncios que no hacían una clara distinción del público al que se dirigen (sin tener en cuenta el target de la revista de la cual se extrae el anuncio), bien porque se dirigen a ambos o bien porque existen dudas a la hora de clasificarlos. Los sujetos que participaron fueron 60 sujetos. Éstos fueron elegidos aleatoriamente, de acuerdo con las variables de edad y género. La 
edad fue determinada por franjas, que comprendían: menores de 20 años; de 21 a 30 años; de 31 a 40 años; de 41 a 50 años y de 51 a 60.

\section{Procedimiento}

El procedimiento, se llevó a cabo por medio de un cuestionario presencial, compuesto de 112 anuncios gráficos a color, en el que se pedía a los encuestados su edad, género, y que marcaran con una " $X$ " qué emoción le sugería cada pieza publicitaria. Las siete alternativas posibles fueron: tristeza; alegría; sorpresa; asco; miedo; ira; o ninguna. Se escogieron dichas respuestas, porque corresponden con las 6 emociones primarias o básicas. Hay que destacar que en el análisis de los resultados sólo se tuvieron en cuenta las respuestas de las casillas "alegría" y "ninguna". Simplemente se incluyeron el resto de posibilidades (tristeza, ira, miedo, asco y sorpresa) en el cuestionario, para hacer que las respuestas de los encuestados fueran lo más sinceras posibles. De este modo, fueron los propios encuestados los que eligieron qué anuncios eran alegres y qué anuncios no eran emotivos. Posteriormente, se analizaron las respuestas de los encuestados con el grafismo de los anuncios. De acuerdo con Costa (1992), el sistema gráfico está definido por cuatro categorías: texto, imágenes, grafismos y color, correspondientes al código verbal y visual. El signo lingüístico se identifica con el slogan, texto y marca, por su tamaño y por su posición. El icono es la imagen que se utiliza para representar a la marca (COSTA, 2004; VILLAFAÑE; MÍNGUEZ, 2000). El grafismo son los recursos tipográficos y el color es el componente cromático de los anuncios (HELLER, 2004). Y la combinación de éstos puede querer generar 
un impacto emocional (VILLAFAÑE, 2006).

\section{Limitaciones}

Destacamos como una futura posible mejora en el cuestionario, incluir la casilla "otra emoción", como opción alternativa a las expuestas anteriormente. El motivo de esta revisión del cuestionario, es que haya podido darse un malentendido al confundir el encuestado la casilla de respuesta "ninguna emoción", la cual se refería a la posibilidad de que una fotografía no genera en el encuestado ninguna emoción, con la respuesta "ninguna de estas emociones". Aunque el significado de la casilla "ninguna" se explicó a los voluntarios antes de comenzar la encuesta, podría facilitar más el proceso de respuesta, concretar más el sentido de esta casilla entre las alternativas posibles. Hay que subrayar que sería interesante conocer de qué modo aparecían representadas cada una de estas emociones (tristeza, sorpresa, ira, asco y miedo) en la publicidad fotográfica de la prensa española pero no eran relevantes en nuestra investigación y por ello, no fueron analizadas porque nuestro objeto se centra en la alegría.

\section{Resultados y Discusión}

Entre los resultados de la muestra de anuncios gráficos analizados cabe diferenciar cómo se han percibido las emociones en general, tanto emotivas como las que no generaron "ninguna emoción" y como se ha identificado la alegría, en la muestra de anuncios gráficos. 


\section{Percepción de las emociones en general}

Los sujetos encuestados percibieron las fotografías visionadas como emotivas, y como "ninguna emoción". Cuando se indica las emotivas se hace referencia a las emociones básicas que son tristeza, sorpresa, ira, asco, miedo y la alegría y por la "ninguna emoción" es cuando el encuestado no percibe ninguna emoción básica en el anuncio de la muestra. El 40,8\% de los 112 anuncios gráficos que se mostraban, fueron considerados "ninguna emoción", sin hacer distinción por sexo. Diferenciando el sexo de los entrevistados, se obtuvo que el 39\% de los anuncios fue considerado como "ninguna emoción" por las mujeres, y el 44\% por los hombres. Se observa que los hombres tienen mayor dificultad para percibir las emociones en la publicidad fotográfica, ya que sus respuestas de ninguna emoción" son un 5\% más que en el caso de las mujeres. Del mismo modo, un 40,8\% de las respuestas (si no diferenciamos los géneros) representa un porcentaje bastante alto, por lo que se podría decir que la publicidad fotográfica de la prensa española, no es especialmente emotiva. En cuanto a las emociones que se percibieron como "ninguna emoción", se corresponden principalmente con los anuncios de "Galería del coleccionista", "Bio-Oil", "Vinocu", "Seat León", "Vichy Laboratoires" y "Mercedes-Benz Fashion Week Madrid" (Ilustración 1). Este resultado llama la atención con la proliferación de los estudios de la alegría en los últimos años que demuestran que las emociones positivas ayudan a aumentar la calidad de vida de los sujetos y que para la publicidad puede generar una imagen de marca favorable entre sus públicos (GARCÍA FERNÁNDEZ-ABASCAL, 2009; 
LÓPEZ-CEPERO BORREGO; FERNÁNDEZ JIMÉNEZ; SENÍN CALDERÓN, 2009; VECINA JIMÉNEZ, 2006), véanse los anuncios en la Ilustración1.

Ilustración 1 - Anuncios gráficos "Ninguna emoción": Anuncio Galería del coleccionista; Anuncio Bio-oil; Anuncio Seat Leó; Anuncio Vinocu.
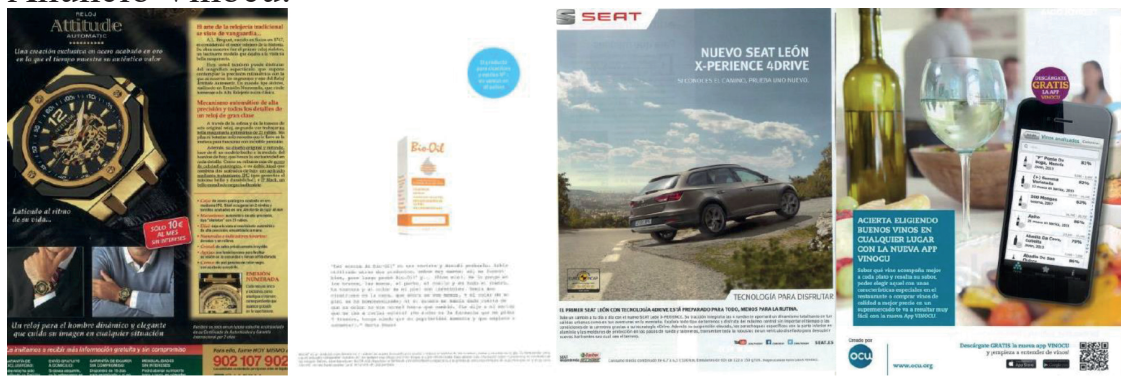

Fuente: El País, Enero 2015; Revista Woman Madame Figaro,nº 268, enero de 2015; Muy Interesante, $n^{\circ}$ 405, febrero 2015; Muy Interesante, $n^{\circ}$ 405, febrero 2015.

a) La fotografía del "Galeria del coleccionista" obtuvo un $88,33 \%$ del total de los cuestionarios respondidos. 53 respuestas en total, de los cuales 35 de esas respuestas fueron de mujeres, y 18 de hombres. La fotografía de "Bio-Oil", fue respondida un $85 \%$ del total de los cuestionarios, con 51 respuestas en total. De estas, 33 fueron de mujeres, y 18 respuestas de hombres. Quedan con la misma puntuación, un 75\% del total de las respuestas, las fotografías de "Vinocu" (con 27 respuestas de mujeres y 18 de hombres), "Seat" (con 30 respuestas de mujeres y 15 de hombres), "Vichy Laboratoires" (con 31 respuestas de mujeres y 14 de hombres) y "Mercedes-Benz Fashion Week Madrid" 
(con 27 respuestas de mujeres y 18 de hombres). De estas fotografías, llama la atención la impersonalidad e inexpresividad general en todas ellas. Esto se debe a que la mayoría de estos anuncios, no son fotografías basadas en una estrategia publicitaria emocional, por lo que los elementos compositivos que las diseñan, no están enfocados a persuadir emocionalmente (LÓPEZ VÁZQUEZ, 2007; TELLIS; REDONDO, 2002). El código verbal por ejemplo, tiene un aspecto formal con tipografías simples en todos los anuncios. Únicamente se ha modificado el color, tamaño o tipo fuente, en aquellos logotipos que lo requieran o para resaltar alguna frase concreta (claim). En cuanto al contenido del texto, sólo en dos de las fotografías se observan mayor intento de seducción. En la fotografía publicitaria de "Galería del coleccionista", que es la menos emotiva de toda la muestra. Aunque se haya querido aparentemente generar de forma equilibrada un mensaje racional y emotivo, el resultado para el espectador es que es la parte estética de la composición (BRIÑOL, et al., 2007) sea vista por los encuestados como "nada emotiva". En cuanto a la fotografía del "Seat León", se identifica que el código lingüístico no es el primer protagonista ya que el texto está muy reducido mediante una tipografía pequeña frente al producto anunciado, que tiene mayor protagonismo (MARTÍNEZ-PASTOR; MONTES-VOZMEDIANO, 2015). Sin embargo, la imagen por sí sola no connota 
un mensaje inequívoco de libertad, novedad o aventura, como pretende el anunciante. Igual que en el caso anterior, la mayor emotividad del anuncio reside en el texto y esto genera que pase desapercibida. Tal y como apuntan Briñol et al. (2007) el mensaje racional tiene como característica que se incluye una argumentación raciona de datos y evidencias a través de la reflexión y de la lógica, lejos de generar apelaciones emotivas. Mientras que en el código visual no se observa una línea compositiva común todos los objetos materiales se corresponden con el producto que se publicita. Sólo en una fotografía, "Vichy Laboratoires", se representa la figura humana compartiendo protagonismo con el producto anunciado, la crema. En este caso, tanto la apariencia sobria como el gesto distante e inexpresivo de la modelo (habitual en los sectores de cosmética y moda femenina de lujo), refuerzan el que no haya "ninguna emoción” en la campaña publicitaria. Se observa que no se han aprovechado las posibilidades connotativas que poseen el color, la textura, el marco, el encuadre, la composición, las formas y líneas, la iluminación o la espacialidad para generar la emoción tal y como apuntaba Villafañe (2006).

b) Las fotografías publicitarias que los encuestados percibieron con carga emotiva (tristeza, sorpresa, ira, asco, miedo y la alegría), fueron un 28,54\% del total de la muestra de los anuncios. Entre las más emotivas, los entrevistados indicaron los anuncios de "Tampax Pearl", "Tous", El 
Corte Inglés", "Fisherman's Friend" y "Barceló Viajes" (véanse los anuncios en la Ilustración 2).

Ilustración 2 - Anuncios gráficos "Emotivos": Anuncio Tampax Pearl; Anuncio Tous; Anuncio El Corte Inglés; Anuncio Fisherman's Friend; Anuncio Barceló Viajes.
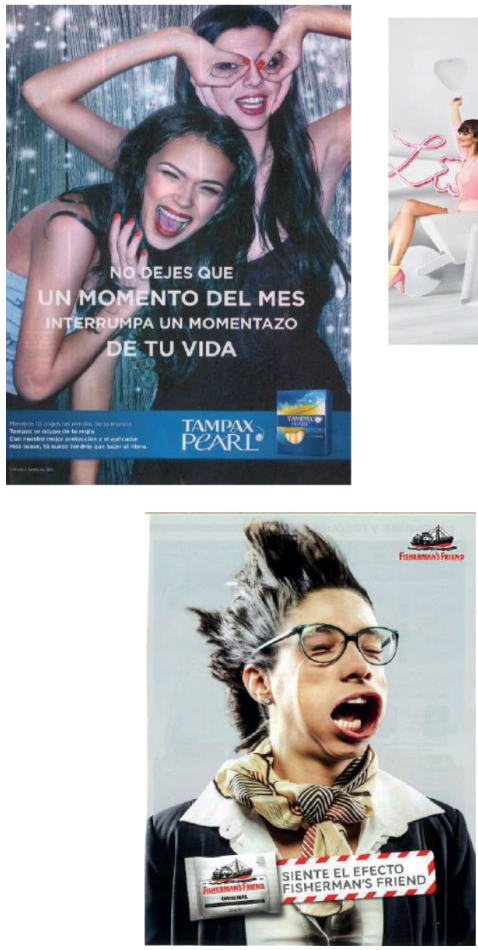

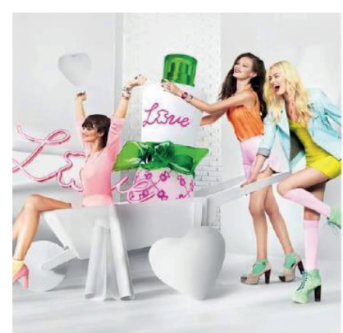

Lisue

mous
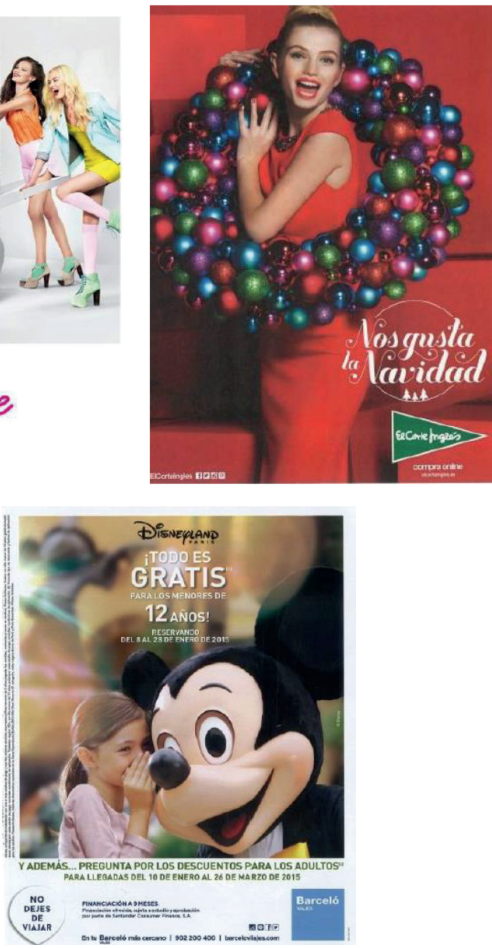

Fuente: Revista Cuore, n. ${ }^{\circ}$ 458, Febrero 2015; Revista Cuore Stilo, n. ${ }^{\circ} 44$, Diciembre 2014; Revista Cuore Stilo, n. ${ }^{\circ}$ 45, Enero 2015; Revista Muy Interesante, n. ${ }^{\circ}$ 405, Febrero 2015; El País Semanal, n. ${ }^{\circ}$ 1988, Enero 2015.

La fotografía de "Tampax Pearl" se percibió emotiva en un $6,66 \%$ del total, es decir, que un $93,34 \%$ de las respuestas se percibieron con alguna de las emociones básicas (tristeza, alegría, sorpresa, ira, miedo o asco). En la misma línea, la publicidad 
de "Tous" y la del "El Corte Inglés" obtuvieron una puntuación del $8,33 \%$, lo que supone que un $91,67 \%$ tenían relación con las emociones básicas. y en tercer lugar, las fotografía de publicidad de "Fisherman's Friend y de "Barceló Viajes" representan un 90\% de las respuestas de emociones básicas (ANDRADE CABRERA; MORALES GARCÍA, 2012; CHÓLIZ MONTAÑÉS, 2005; EKMAN, 1992; GARCÍA FERNÁNDEZ ABASCAL et al., 2010). Tal y como indican Briñol et al. (2007) se han percibido como emotivos los anuncios que tienen una mayor carga visual que verbal debido a que el receptor conoce la marca y no es necesario argumentar nada al respecto sino recordarle y reforzar la marca, como es estos casos. De hecho, el escaso texto que aparece se reserva para el logotipo, para complementar el mensaje visual y/o para el claim del anuncio. Los signos figurativos destacan, porque en todas las fotografías aparecen personas. Se representan sus gestos, expresiones faciales y posturas, que indican que están experimentando momentos agradables o divertidos totalmente reconocibles por todos, tal y como García Fernández Abascal et al. (2010). En la fotografía "Fisherman's Friend" no se representa un momento agradable en sí, pero el gesto del modelo representado, ha sido manipulado para aportar humor al anuncio, lo que hace que éste resulte expresivo, y también grato a ojos del espectador. La utilización de ciertos símbolos como, los corazones en la fotografía "Tous Love", la guirnalda de bolas navideñas en la "El Corte Inglés" o el famoso personaje Mickey Mouse en la "Barceló viajes", hace que se enfatice aún más la emotividad de cada anuncio. Esto se debe a que todos ellos se pueden relacionar con momentos de enorme carga afectiva. También se han aprovechado los signos plásticos 
para aumentar la expresividad de estos anuncios. En los anuncios de "Tampax", del "El Corte Inglés" y de "Fisherman's Friend" no aparecen signos plásticos, que consigan que el espectador se sienta parte de la escena que contempla. Mientras que en la publicidad de “Tous" y de "Barceló viajes", el espacio está delimitado mediante una forma rectangular, simulando una ventana por la cual el espectador observa la escena, para hacer partícipe al receptor de la escena. El uso del color adquiere valor connotativo en sólo dos de las fotografías, pero en ambas es uno de los elementos principales dentro de la composición (HELLER, 2004). En la fotografía de "Tous", se emplean tonos suaves y alegres que provocan un bienestar como el amarillo, el verde, el rosa o el naranja, tanto para la ropa de las modelos como para el frasco de perfume para acentuar la informalidad de la escena (HELLER, 2004). En la fotografía de "El Corte Inglés" el color predominante es el rojo, el cual, aparte de ser uno de los que más atrae la atención y que está especialmente asociado con el amor, la pasión y el erotismo, es decir con las emociones (HELLER, 2004). En el anuncio de “Tous” se juega también con el elemento de la escala (aumentándola en el frasco de perfume), para recalcar más el carácter sorprendente y recreativo de la escena representada. Se entiende que estas campañas publicitarias, se perciben como emotivas frente a las anteriores que no se destacan por ninguna emoción.

\section{Percepción de la emoción de la alegría}

Mientras que de los 112 anuncios un 30,66\% de los encuestados percibieron alegría. Los hombres percibieron la alegría 
en la muestra de las fotografías en un $26 \%$ de las ocasiones, las mujeres un 33\% de las veces y teniendo en cuenta ambos sexos, éstos percibieron un 31\% de las ocasiones la alegría. Aparentemente las mujeres tienen mayor facilidad que los hombres a la hora de percibir alegría en la publicidad fotográfica de prensa española, ya que sus respuestas fueron un 7\% más que en el caso de los hombres. Sin embargo, este resultado está limitado a la muestra analizada dado que los encuestados varones son menos que las mujeres y las muestras de las revistas en su gran mayoría está dirigida a mujeres, excepto uno que es solo para el target masculino. Mientras que sí es relevante que entre el total entre hombres y mujeres se percibió que un 30,66\% de los anuncios del cuestionario son alegres; un 40,8\% no generaron ninguna emoción a los encuestados; y un 28,54\% de los anuncios generaron tristeza, ira, asco, sorpresa o miedo (Gráfica 1). Estos datos indican que un 59,2\% de la publicidad fotográfica española es percibida como emotiva, y que, de ese porcentaje, un $30,66 \%$, se identifica con la alegría. Estos datos indican que es una emoción representativa en la publicidad fotográfica. Esto refuta la hipótesis de partida y la convierte en nula, dado que los resultados obtenidos indican que la publicidad fotográfica española es percibida como emotiva, porque un 59,2\% de los encuestados percibieron alguna de las emociones primarias, y entre ellas un $30,66 \%$ se percibieron como alegría, frente a un 40,8\% de los casos que no sugirieron ninguna emoción.

a) Las fotografías publicitarías que se percibieron por los encuestados como más alegres son: "Tous", "Tampax", "Barceló Viajes" y "Cerveceros de 
España". Estas fotografías coinciden con las que sugirieron alguna emoción. Se añade las fotografías de "Cerveceros de España", que se percibe como alegre al margen de cualquier otra emoción. Esto indica que estas publicidades, además de ser percibidas como las más alegres, son además las que más poder emocional tienen. Son claros ejemplos de publicidad fotográfica española emocional. La fotografía de "Tous" fue respondida como alegre en un $90 \%$ del total, 38 de esas respuestas, fueron de mujeres y 16 de hombres. Los anuncios de "Tampax" y "Barceló Viajes", tuvieron una percepción del 83,33\% del total de las respuestas, de los cuales 37 respuestas fueron de mujeres y 16 de hombres. La fotografía "Cerveceros de España" obtuvo 47 respuestas en total, lo que equivaldría a un 78,33\% del total, 30 de esas respuestas fueron de mujeres y 17 de hombres. Las características que resaltan de estos anuncios más alegres son: la prevalencia del código visual sobre el código verbal y la utilización del color. De acuerdo con Briñol et al. (2007) hay una prevalencia del mensaje emocional frente al racional recurriendo a sentimientos para provocar empatía o afecto. Esto se consigue resaltando en el código visual la utilización de signos icónicos/figurativos correspondientes a modelos femeninas. Estas figuras muestran la inconfundible expresión facial de la alegría, la sonrisa. Su postura corporal refleja diversión o relajación (GARCÍA FERNÁNDEZ-ABASCAL, et al., 2009). Además, en 
todos los anuncios los momentos representados son momentos de ocio que reflejan situaciones divertidas, relajadas o desenfadadas. Aunque en alguno de estos ejemplos el fondo sobre el cual sucede la escena, sea abstracto, diáfano e impersonal, como es el caso de las fotografías de "Tous", y en otros aparezca ligeramente desenfocado como es el anuncio de "Barceló viajes", “Cerveceros de España” y "Tampax", sí que ayudan a situar el contexto lo suficiente, como para resaltar aún más la alegría que transmite la escena principal. Mientras que el texto es escaso y se limita a los logotipos y/o el claim del anuncio. También se utiliza para ampliar la información del producto o servicio, ocupando una proporción escasa frente al resto de la composición. $\mathrm{Su}$ aspecto es sencillo y legible, pero en un segundo plano. Los colores no se emplean como mensaje connotativo, excepto en el caso de "Tous" en el cual mediante un juego de contrastes entre los colores claros y alegres, de la ropa, complementos o detalles del recipiente del producto, y el blanco que protagoniza la composición (véase el anuncio de Cerveceros de España en la Ilustración 3). 
Ilustración 3 - Anuncio Cerveceros de España.

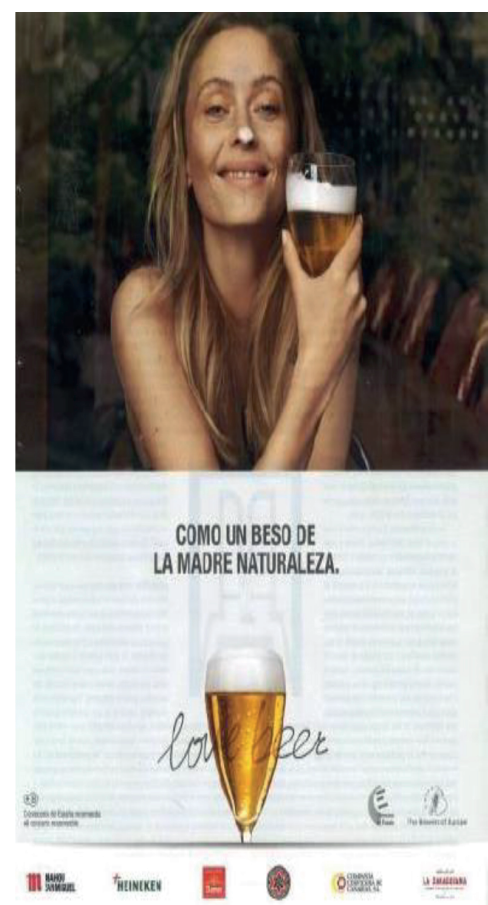

Fuente: El País Semanal, nº 1999, enero 2015.

b) Las fotografías publicitarias que se percibieron en la categoría de alegre pero menos que las analizadas anteriormente son las de los anuncios de "Galería del coleccionista" (anteriormente indicada) y la de "Bacardí". Éstos solo tuvieron una respuesta de haber sido percibidas como alegres, lo que equivale al 1,66\% del total. Le siguen a estas, los anuncios de "Audi", "Biooil", "Arriaga Asociados"y "Galería del Coleccionista", que obtuvieron 2 respuestas de alegría, lo que equivale al 3,33\% del total. Frente a las fotografías de "Volvo" 
110 Representación y percepción de emoción de la alegría en la fotografía publicitaria

y "Bosch", que no obtuvieron ningún voto de alegría (véanse los anuncios en la Ilustración 4).

Ilustración 4 - Anuncios poco alegres: Anuncio Galería del Coleccionista/Croix du sud; Anuncio Bacardí; Anuncio Arriaga Asociados; Anuncio Volvo; Anuncio Bosch.
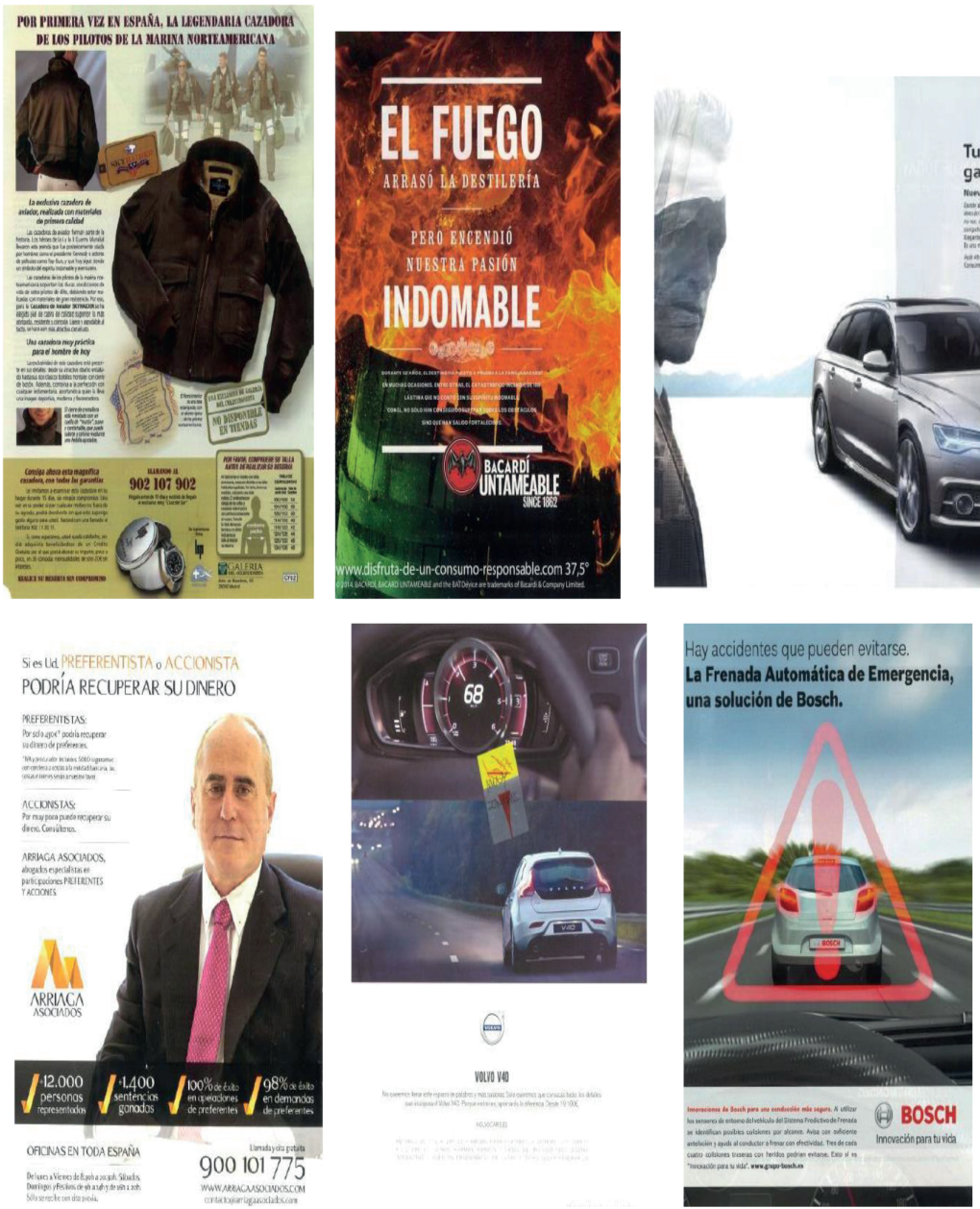

Fuente: El País Semanal, no 2002, Febrero 2015; ICON, n. ${ }^{\circ}$ 13, Enero/Febrero 2015; El País Semanal, $n^{\circ}$ 2002, Febrero 2015; Revista Muy Interesante, $n^{\circ}$ 405, Febrero 2015; Revista Muy Interesante, $\mathrm{n}^{\circ}$ 405, Febrero 2015. 
En esta categoría se identifican dos tipos de fotografías publicitarias: unas que han sido mencionadas entre los anuncios menos emotivos, que son "Galería del coleccionista" y "Bio-Oil" y alguna fotografía que se encuentra entre los diez anuncios más emotivos, como la fotografía de "Bacardí". De esta manera se identifican anuncios que son poco alegres y nada emotivos, y otros anuncios poco alegres, pero muy emotivos.

En estos anuncios alegres con menor puntuación que los anteriores. Si bien en cierto que en algunas de ella hay una prevalencia del código visual que el textual el mensaje es argumentativo (BRIÑOL et al., 2007). Se destaca la escasa presencia de figuras humanas protagonistas y en las imágenes no se generan expresiones faciales vinculadas con la alegría como la sonrisa, además se (GARCÍA FERNÁNDEZ ABASCAL et al., 2010). También se utiliza el aumento del tamaño de la tipografía, para resaltar el claim publicitario, y la modificación del color, forma y tamaño en el logotipo de la marca (VILLAFAÑE, 2006). Las formas y las líneas se emplean en algunas campañas, sólo para dirigir la mirada y para subrayar aquellas partes visuales o textuales importantes dentro de la composición contribuyendo a un mensaje más racional con un claro distanciamiento de emotividad en las piezas publicitarias. Los colores más predominantes son el negro, el blanco y el gris que connotan según Heller (2004) correlativamente el duelo, el final, lo pesado, la pureza, la inocencia, el aburrimiento y la vejez, entre otras, alejándose de la emoción de la alegría. Por estos motivos dichas campañas publicitarias, han sido percibidas como de escasa alegría. 


\section{Conclusiones}

La publicidad fotográfica española sí genera emociones, dado que los resultados indican que, de la muestra, un 59,2\% de los encuestados perciben emociones, cualquiera de las básicas, y un 30,66\% específicamente la alegría, aunque ésta sea interior y subjetiva (CHÓLIZ MONTAÑÉS, 2005; REEVE, 1992). De ese porcentaje solamente un $30,66 \%$, identifica la publicidad fotográfica como alegre, dato que indica que es una emoción representativa en los anuncios esencialmente por composición visual y los colores utilizados que genera esta emoción. Los anunciantes parecen que establecen diferencias de género ya que habitualmente emplean conceptos o elementos entendidos como menos emotivos o emocionalmente serios, para dirigirse a un target masculino. Esto puede ocurrir por la idea estereotipada que aún existe de la masculinidad. Es de destacar que la emotividad de las campañas, está estrechamente relacionada con el tipo de producto que se anuncia. Así cuanto más exclusivo es el objeto, menos emociones emplea la campaña, para promover elegancia disociada con emotividad. La publicidad fotográfica española suele recurrir con frecuencia a la pose, actitud y expresión de las figuras humanas, para conseguir identidad en las emociones (GARCÍA FERNÁNDEZ ABASCAL et al., 2010). De hecho, cuanto mayor es la relevancia del código visual mayor es la emotividad. También se suele utilizar el humor como recurso, para sugerir emociones positivas que a menudo se asemejan a la alegría. Por todo ello, se podría decir que, en la actualidad, la publicidad fotográfica de la prensa española no está explotando las posibilidades que ofrecen las técnicas compositivas, 
que ayudan a sugerir más emoción en los mensajes visuales. A pesar de que ésta se perciba alegre. Por lo tanto, habría que reflexionar acerca de la necesidad de actualizar los diseños empleados para la publicidad fotográfica de la prensa española, con el fin de conseguir un acercamiento mayor al consumidor, que obtenga mejores resultados en relación a la percepción emocional y alegre de la publicidad fotográfica española.

\section{Referencias}

ANDRADE CABRERA, Verónica; MORALES GARCÍA, Mónica. Conociendo las emociones. In: ___ Propuesta para una educación socioemocional en niños y niñas de 4 a 5 años. Tesis (Pregrado en Psicología) - Facultad de Psicología de la Universidad de Cuenca, Cuenca, 2012. p.17-38.

BERMEJO BERROS, Jesús. La publicidad fuera de la publicidad: un gesto torero. Pensar la Publicidad, Madrid, v. 4, n. 2, p. 9-16, 2010.

BRIÑOL, Pablo et al. Cambio de actitudes a través de la comunicación. En: MORALES, Francisco et al. (Coord.). Psicología Social, Madrid: McGraw-Hill, 2007.

CÁCERES ZAPATERO, María Dolores; DÍAZ SOLOAGA, Paloma. La representación del cuerpo de la mujer en la publicidad de revistas femeninas. Estudios sobre el mensaje periodístico, Madrid, v. 14, p. 309-327, 2008.

CODELUPPI, Vanni. El papel social de la publicidad. Pensar la Publicidad, Madrid, v. 1, n. 1, p. 149-155, 2007.

COSTA, Joan. La imagen de marca: un fenómeno social. Barcelona: Paidós, 2004. 
COSTA, Joan. Los recursos combinatorios del grafismo funcional. In: MOLES, Abraham; JANISZEWSKI, Luc (Comp.). Grafismo Funcional. Barcelona: Ediciones CEAC, p. 121-151, 1992.

CHÓLIZ MONTAÑÉZ, Mariano. Psicología de la emoción: el proceso emocional. Valência: Universidad de Valencia, 2005. Disponible en: $<$ http://www.uv.es/choliz/Proceso\%20emocional. pdf $>$. Acceso en: 1 mar. 2016.

CHUANG, Shih; LIN, Hung-Ming. The effect of induced positive and negative emotion and openness-to-feeling in student's consumer decision making. Journal of Business and Psychology, New York, US, v. 22, n. 1, p. 65-78, 2007.

DÍAZ SOLOAGA, Paloma. Valores y estereotipos femeninos creados en la publicidad gráfica de las marcas de moda de lujo en España. Anàlisi, Barcelona, v. 35, n. 27-45, 2007.

EKMAN, Paul. An argument for basic emotions. Cognition and Emotion, Hove, GB, v. 3, n. 4, p. 169-200, 1992.

FARRELLY, Matthew C. et al. Promotion of smoking cessation with emotional and/or graphic antismoking advertising. American Journal of Preventive Medicine, New York, US, v. 43, n. 5, p. 475-482, 2012.

FRIJDA, Nico. The law of emotion. In: PARROTT, W. Gerrod. (Ed.). Emotions insocial psychology: essential readings. Philadelphia, PA: Psycology Press, 2001. p. 57-69.

GAONA PISONERO, Carmen; MARTÍNEZ PASTOR, Esther. La presencia ethnic en la publicidad institucional. Revista Científica de Información y Comunicación/IC, Sevilla, ES, v. 5, p. 326374, 2008. 
la emoción. Madrid: Editorial Universitaria Ramón Areces, 2010.

GARCÍA FERNÁNDEZ ABASCAL, Enrique. Emociones positivas. Madrid: Pirámide, 2009.

HAMM, Alfons; SHUPP, Harald Thomas; WEIKE, Almut I. Motivacional organization of emotions: autonomic changes, cortical, responses, and réflex modulation. In: DAVIDSON, Richard; SHERER, Klaus R.; GOLDSMITH, Hill. (Coord.). Hansbook of affective sciences. Oxford: University Press, 2003. p. 187-211.

HELLER, Eva. Psicología del color: cómo actúan los colores sobre los sentimientos y la razón. Barcelona: G. Gili, 2004.

HOLBROOK, Morris; BATRA, Rajeev. Assessing the role of emotions as mediators of consumer responses to ad-vertising. Journal of Consumer Research, Chicago, IL, v. 14, n. 3, p. 404420, 1987.

HOLBROOK, Morris; O'SHAUGHNESSY, John. The role of emotion in advertising. Psychology \& Marketing, New York, US, v. 1, n. 2, p. 45-64, 1984.

KAMP, Edward; MACINNIS, Deborah. Characteristics of portrayed emotions i commercials: when does what is shown in ads affect viewers. Journal of Advertising Research, New York, US, v. 35, n. 6, p. 19-28, 1995.

KLEINGINNA, Paul; KLEINGINNA, Anne. Categorized list of emotion definitions, with suggestions for a consensual definition. Motivation and Emotion, New York, US, v. 5, n. 4, p. 345-379, 1981.

LEWIS, Ioni M.; WATSON, Barry; WHITE, Katherine M. Response efficacy: the key to minimizing rejection and 
maximizing acceptance of emotion-based anti-speedin messages. Accident Analysis \& Prevention, Elmsford, US, v. 42, n. 2, p. 459-467, 2010.

LIPOVESKY, Guilles. La felicidad paradójica. Barcelona: Anagrama, 2007.

LÓPEZ VÁZQUEZ, Belen. Publicidad emocional: estrategias creativas. Madrid: ESIC, 2007.

LÓPEZ-CEPERO BORREGO, Javier; FERNÁNDEZ JIMÉNEZ, Eduardo; SENÍN CALDERÓN, Cristina. Diez referencias destacadas de: Psicología Positiva. Anuario de Psicología Clínica y de la Salud, Sevilla, ES, v. 5, p. 49-55, 2009.

MARTÍNEZ-PASTOR, Esther; MONTES-VOZMEDIANO, Manuel. Pain in advertising: an analysis of the content and design of the advertisements in press after 11-M terrorist attacks. Communication \& Society, Pamplona, ES, v. 28, n. 1, p. 115 $127,2015$.

MARTÍNEZ RODRIGO, Estrella; SEGURA GARCÍA, Rosario. El discurso emocional en la publicidad audiovisual de la DGT. Estudios sobre el Mensaje Periodístico, Madrid, ES, v. 19, n. esp., p. 863-872, abr. 2013.

MONTOYA VILAR, Norminanda. La voz de los anuncios y su eficacia persuasiva en los niños. ZER: Revista de Estudios de Comunicación, Barcelona, ES, v. 5, n. 8, p. 67-92, mayo 2000.

OLNEY, Thomas; HOLBROOK, Morris; BATRA, Rajeev. Consumer responses to advertising: the effects of ad content, emotions, and attitude toward the ad on viewing time. Journal of Consumer Research, Oxford, v. 17, n. 4, p. 440-453, 1991.

RAMOS SERRANO, Marina; RUBIO HERNÁNDEZ, María del 
Mar. Identidad cultural en la publicidad de bebidas alcohólicas.

Pensar la Publicidad, Madrid, v. 5, n. 2, p. 205-231, 2011.

REEVE, John. Motivación y emoción. Madrid: McGraw Hill, 1994.

SALANOVA, Marisa; MARTÍNEZ, Izabel; LLORENS, Susana. Psicología organizacional positiva. In: PALACÍ DESCALS, Francisco José (Coord.). Psicología de la organización. Madrid: Pearson Prentice Hall, 2004. p. 349-373.

SÁNCHEZ GARCÍA, Rubén. Publicidad de bebidas alcohólicas. Algunas razones para establecer unos límites. Adicciones, Palma de Mallorca, ES, v. 14, n. 5, p. 133-219, 2002.

SÁNCHEZ REVILLA, Miguel Àngel. Estudio InfoAdex de la inversión publicitaria en España 2014. 2014. Madrid: INFOADEX, S.A. Disponible en: <http://www.infoadex.es/ resumen_estudio_2014.pdf>. Acceso en: 1 mar. 2016.

SCRETTI, Francesco. Publicidad en la política, política en la publicidad. Pensar la Publicidad, Madrid, ES, v. 6, n. 1, p. 35-61, 2012.

TELLIS, Gerard; REDONDO, Ignacio. Estrategias de publicidad y promoción. Madrid: Pearson Addison-Wesley, 2002.

VECINA JIMÉNEZ, María Luisa. Emociones positivas. Papeles del Psicólogo, Madrid, ES, v. 27, n. 1, p. 9-17, 2006.

VILLAFAÑE, Justo. Introducción a la teoría de la imagen. Madrid: Pirámide, 2006.

VILLAFAÑE, Justo; MÍNGUEZ, Norberto. Principios de teoría general de la imagen. Madrid: Pirámide, 2000. 